\title{
ANNALS of THE NEW YORK ANNALS ACADEMY Of SCIENCES
}

\section{Between progress and obstacles on urban climate interdisciplinary studies and knowledge transfer to society}

\begin{tabular}{|r|l|}
\hline Journal: & Ann NY Acad Sci \\
\hline Manuscript ID & annals-1738-007.R1 \\
\hline Manuscript Type: & Perspective \\
\hline Date Submitted by the Author: & n/a \\
\hline Complete List of Authors: & $\begin{array}{l}\text { Hidalgo, Julia; Laboratoire Interdisciplinaire Solidarites Societes Territoires, } \\
\text { CIEU } \\
\text { Lemonsu, Aude; Météo-France/CNRS, Centre National de Recherches } \\
\text { Météorologiques / Groupe d'Etude de l'Atmosphère Météorologique } \\
\text { MASSON, Valéry; Météo-France/CNRS, Centre National de Recherches } \\
\text { Météorologiques / Groupe d'Etude de I'Atmosphère Météorologique }\end{array}$ \\
\hline Keywords: & $\begin{array}{l}\text { urban climatology, urban data, climate impacts, urban planning, urban } \\
\text { climate maps }\end{array}$ \\
\hline & \multicolumn{2}{|c|}{} \\
\hline
\end{tabular}

SCHOLARONE ${ }^{m}$

Manuscripts 


\title{
Between progress and obstacles on urban climate interdisciplinary studies and knowledge transfer to society
}

\author{
Julia Hidalgo ${ }^{1}$, Aude Lemonsu ${ }^{2}$, Valéry Masson ${ }^{2}$ \\ 5 1, National Center of Scientific Research (CNRS), Laboratoire Interdisciplinaire Solidarités, Societés (LISST), \\ Interdisciplinary Center of Urban Studies (CIEU)
}

2, National Center of Meteorological Research, Météo-France/CNRS

Julia Hidalgo, 5, Allées Antonio Machado, Maison de la Recherche, B421bis, Toulouse Federal University, 31058,

10 Toulouse, France julia.hidalgo@univ-tlse2.fr

Keywords: urban climatology, urban data, climate impacts, urban planning, urban climate maps

\section{Abstract:}

Cities modify their local climate and at the same time they suffer from the local impacts of climate change. This paper 15 comments on progress and obstacles in three active research topics that contribute to increasing the capacity of knowledge transfer to society within the urban climate research community. The first is linked to the production of urban surface description useful for urban climate studies. The conceptualization of 'Local Climate Zones' is now widely used to represent urban climate variability at the neighborhood scale. Land-use, morphological, architectural, and social data are also needed and those are being gathered using different approaches. The second is linked to the

20 necessity of producing information directly connected to the effects on society. This requires a strong multidisciplinary approach and nowadays, impact studies are not limited to one dimension but instead cover multiple dimensions. Finally, the third is to transfer all this information to city practitioners, so that urban climate features are considered, among many other aspects, in city management. For urban planning, the introduction of cartographic tools encompasses urban climate diagnosis as well as recommendations for future urbanization.

\section{Introduction}

A distinctive urban climate is created by the presence of a city that disrupts local and regional atmospheric features by altering the surface-air exchanges of heat, moisture, mass and momentum ${ }^{1}$. This effect is present on all

30 scales and impacts every meteorological variable and its magnitude. It depends on the city's physical structure (urban form) and pattern of occupation (urban function). The most widely studied and mediated urban climate effect is the urban heat island (UHI), which describes the differences in surface, sub-surface and air temperatures in cities when compared to the surrounding 'natural' environment ${ }^{2}$. Other impacts include changes in turbulence and general flow dynamics as the overlying air adjusts to the complex urban surface which influences the dispersion of air pollutants and heat emitted near the ground ${ }^{3}$.

Urban Climatology has become both an international and interdisciplinary research field. The transnational diffusion of research developments on urban climatology within the research sphere has been successful for some decades. Historically, this knowledge circulation has rested on meetings organized under the auspices of major 40 international networks such as the World Meteorological Society (WMO), the Conféderation Internationale du Batiment (CIB), the International Federation for Housing and Planning (IGHP), the International Society of Biometeorology (ISB), the World Health Organization (WHO) and, more recently, the International Association of Urban Climate (IAUC). Hebbert, M. \& F. Mackillop ${ }^{4}$ gave a very accurate account of the dissemination of this knowledge, starting in the late 1950s in Davos with an international working group on urban climatology involving IFHP, ISB and CIB, until the present day, when IAUC took over the cycle of conferences and the structuring of research networks on the international scale. This successful international research collaboration and its consequent knowledge exchange and network development can be explained by the fact that key figures in urban climate research participated in these international structures in various capacities. This continues to be the case today, as some IAUC members are deeply involved in WMO or ISB, for example.

While it is common to refer to L. Howard's pioneering work at the beginning of the 19th century and later to T. R. Oke as a great contributor boosting the field from the 1970s, research production describing atmospheric conditions over 
urban areas has accelerated during the last decade, taking advantage of the development of new numerical modelling technologies and attracting an increasing number of scientists from different disciplines and locations all over the world. Physical geographers and experts on atmospheric physics dominated this field in its early years, orienting the scope and the applied methods to studies of the outdoor environment, while architects were, generally speaking, more concentrated on studying the indoor micro-climatic conditions at the building scale. These studies examined both the impact of urban development upon all aspects of the atmosphere and the response of populations to the resulting

60 climate. Spatial scales covered upward from the scale of the building or the street to that of the whole city. A gradual broadening has taken place in recent years including studies on fields such as urban air pollution, urban hydrology, building climatology, urban vegetation and urban planning, incorporating specialists and enriching the research field.

Urban climate science has made significant progress in linking the properties of the urban surface cover, 65 including its extreme spatial heterogeneity, to changes in the overlying atmosphere called the Urban Boundary Layer (UBL). Significant gaps in the understanding of processes do remain, but it is generally acknowledged that the outstanding issue for urban climate science is the need to transfer knowledge into urban decision-making. Efforts to transfer knowledge to society started very early, as attested for example by Kassner's book "The Meteorological Basics of City Planning" published in German in 1918, and the reader will find a comprehensive review in Hebbert and

70 MacKillop ${ }^{4}$, but coordinated efforts and discussions within the research community at the international scale are more recent. The International Conference on Urban Climatology (ICUC8, August 2012, Dublin, Ireland) included a plenary session on applied studies in urban climatology; three years later, at the ICUC9 (July 2015, Toulouse, France), coinciding with the year of the 21 st session of the Conference of the Parties on Climate Change Policy \& Practice held in December 2015 in Paris, it was clearly decided to focus "on the recent scientific activities on climate change

75 mitigation \& adaptation in urban environments, as well as on the transfer to institutional stakeholders and urban planners to include urban climate considerations in their practices". Concerning transfer of urban climate knowledge, the session dedicated to "Transfer of urban climate knowledge to urban planners" and the session on improving "Urban design with climate" drew strong attendance. Other related sessions were "Bioclimatology and public health", "Outdoor microclimate and comfort", "Indoor comfort \& air quality", "Human perception", "Climate resilient design" as well as

80 those dedicated to "Interdisciplinarity", attesting to the importance of applied research in this domain. The ICUC10, held last summer in New York, consolidated this dynamic, proposing numerous sessions on urban planning and governance, comfort and impact studies.

The specificity of the research findings for each individual field of study makes a comparison of results and the rising generic nature difficult. This should not be understood in terms of results, as knowledge transfer will emerge from widely differing contexts depending on the needs and identity of decision-makers, but in terms of methods and tools. The field needs to transcend local case studies and develop the search for standardization methods, the objective being to develop ways to link climate knowledge and planning knowledge for cities everywhere. That the objective is twofold: first, to allow comparison of research results between locations and second, to take advantage of the 90 observation protocols, modelling and cartographic tools developed in recent decades, mainly in the north. Considerable efforts were made, for example, on experimental protocol guidelines for identifying and studying the impact of cities on atmospheric thermodynamics and atmospheric composition in a comparable manner ${ }^{7}$. The research community also actively developed a rich literature reviewing progress on atmospheric measurements in urban areas and modelling on a variety of scales based on both numerical and experimental approaches ${ }^{8,9,10,11}$.

This paper presents three active research topics that, in our opinion, contribute to increasing the capacity of knowledge transfer to society within the urban climate research community. It aims not so much to draw up an exhaustive review as to give a quick overview of the state of research activity to illustrate where we stand today. These interdisciplinary topics are presented and commented on here mostly through their technical angle, methods and tools, 100 rather than on the basis of their policy implications or how they relate to different categories of end-users, that, in this paper, will refer mostly to urban planners. First (section 2), we present the efforts related to urban data production, putting the accent on the fact that coherent and consistent urban databases suited to urban climate studies containing information on both urban form (land-cover, materials and building dimensions) and function (occupation patterns) are still in the early stages of development. Urban data infrastructure is important both for impact studies in urban environments (section 3) -- to evaluate strategies for adaptation to climate change and urban climate mitigation -- and for the integration of local climate knowledge in urban planning (section 4), where considerable efforts have been made in recent years to bring to light the levers and curbs affecting this integration.

\section{Urban datasets for urban climate studies}

An adequate description of the cities is necessary at all different steps of the process of evaluating cities' strategies for adaptation to climate change and mitigation of urban heat islands. This description encompasses issues regarding the scale as well as the nature of the data.

\section{Scale issues:}


Cities are complex systems in which physical, economic, biological, social and other processes interact. Therefore, the description of a city also encompasses a number of spatial scales, ranging from the individual, housing and buildings, to the neighborhood, the city and the wider conurbation. In urban micro-climatic studies we often focus on 3 different spatial scales ${ }^{12}$ :

- the meso-scale, encompassing the whole city (which is the scale where the Urban Heat Island is typically defined, as for example the difference of temperature between the city center and the countryside).

- the local scale, where neighborhoods experience different micro-climates (e.g. a suburban residential area with gardens and small houses and a commercial area with a lot of car parks next to it)

- and the micro-scale, where variability is governed by individual urban features (cool air below a tree, ventilated street, warm and cool air on two sides of a house, etc.)

Many methods have been used to describe cities at the meso-scale and local-scale, in modelling or analyses in direct

130 link with decision makers. However, this is in general a city-case or model-based approach, that is not sufficiently generic for application in another context. This is why urban climate heterogeneity at the neighborhood scale has been conceptualized by 'Local Climate Zones ${ }^{13}$, which are now widely used by the urban climate community and represent urban areas that are relatively homogeneous in type or urbanization. LCZs represent either the rural landscape (in 7 classes: dense or scattered trees, bush, low plants, bare soil, bare rock, water) or the urban one, more specifically, in ten

135 classes (compact or open high-rise buildings, compact or open mid-rise buildings, compact, open or sparse low-rise buildings, large low-rise buildings, heavy industry, lightweight low-rise buildings).

Because of their relative homogeneity, LCZs are supposed to homogeneously influence the atmosphere on the local scale, producing locally homogeneous air temperatures. Experimental mobile near-ground atmospheric measurements (with cars or bicycles for example) have been performed to assess this, by documenting the inter- and infra-LCZ microclimate variability ${ }^{14,15,16}$. In Figure 1 it is possible to relate the near-surface air temperature with the ground use and building morphology represented by the LCZ.

LCZs represent the urban tissue on the local scale from the urban climate point of view. Furthermore, because they refer

145 to urban structure shapes, they are easily understandable by urban planners, and thus are an efficient way to foster knowledge exchange between meteorologists and urban practitioners. An example of this is shown by the initiative of the Greater Paris urban planning agency to produce LCZ maps of its territory, to represent the potential effect on the micro-climate ${ }^{17}$.

150 The state-of-the-art atmospheric and climate models are not able to represent the whole urban area climate on the micro-scale. They are able to represent hectometric and kilometric scales, respectively. Finest scale processes are then modelled in a simplified manner. For example, all urban canopy models in the atmospheric models represent the complexity of 3D buildings as street canyons or aligned cubes. However, these state-of-the-art models are now able to model both meso and local scales, even for climatic studies over several years. This scale is for example adequate for

155 simulating not only Urban Heat Islands, but also city-induced extreme precipitation events, as can occur in megacities in China or the USA ${ }^{18}$. As the local-scale meteorological model meets the LCZ spatial-scale model, the LCZ approach is a very pertinent description of the city for current urban climate models.

Several actions have been launched in order to provide LCZ-based descriptions of cities for such meteorological urban 160 climate models. To have such information on the whole world, for any urban area in any country, is a challenge. To address that challenge, using satellite images may help. However, most land use at the global scale such as the ESACCI product 1.6.1 of 2016, which focuses on natural and agricultural landscape classifications, only delimits the urban area as a single class. One way to get a description of the intra and inter-city variability is to provide spatialized information on some urban parameters. For example, Dong et al (2017) ${ }^{19}$ determined a global 1-km resolution map of 165 the anthropogenic heat flux, using nighttime light satellite images. Another way is to produce maps with finer urban classifications. Refined urban classifications do exist, but they are generally limited to a region (such as Corine Land Cover over Europe ${ }^{20}$ ).

The most advanced global urban database suitable for environmental and meteorological/climatic studies, to our

170 knowledge, is the Global Human Settlement Layer, at $100 \mathrm{~m}$ of resolution. The classification schema of the settlement distinguishes built-up areas based on vegetation content (from satellite NDVI vegetation index) and volume of buildings, the latter estimated from integration of satellite terrain and elevation data from SRTM and ASTERGDEM $^{21,22}$. Nine urban classes are defined, with an approach very similar to the LCZ, since it is based on the amount of impervious land use and the height of buildings. An ongoing task is the inclusion of this urban database along with

175 LCZs in the second generation of Ecoclimap database ${ }^{23}$, that will then finely describe the vegetated covers (based on ESA-CCI and ancillary data) and urban covers.

LCZ maps of cities, maps that are in principle more precise and expert-based, are awaited from the World Urban 
Database and Access Portal Tools (WUDAPT) initiative. This is an IAUC community-based project to gather a census of cities around the world ${ }^{24}$. The WUDAPT methodology is based on the LCZ-mapping of cities using satellite images, such as landsat ${ }^{24}$, with a common protocol, ensuring a relative homogeneity between each map's representativeness. This protocol is based on an iterative process with expert supervision. First the expert manually defines several neighborhoods for each LCZ present in the city and its surroundings. Second, a classification process is used to classify all the images, that covers the urban area under study. If necessary, the expert completes the first step again to improve

185 the mapping. Finally, a quality control process is carried out. LCZ maps produced this way have proven to be successfully used within atmospheric models ${ }^{26}$. The association of model urban parameters (e.g. building height, building cover) by means of information from LCZs alone is presented in Ching et al (2018) ${ }^{27}$, as well as ways to include finer data when available. All architecture-related information on building construction (e.g., roofing and wall materials, presence of windows) also needs to be defined. Tornay et al $(2017)^{28}$ propose a methodology to gather this

190 information on the regional scale. This will make it possible, for example, to describe how buildings or houses are (differently) built in several regions and countries of the world (e.g. in Western European, Chinese, South-American or Equatorial African cities). In the framework of WUDAPT, two actions have been initiated to achieve this: by crowdsourcing, with development of mobile app surveys, and by collaboration with architects at the global level. For the latter, the Passive Low Energy Architecture (PLEA) association joined the WUDAPT initiative along with IAUC,

195 enlarging the WUDAPT scope in terms of scientific methodology as well as potential users. A mixed working group of architects and climatologists from 20 countries was formed during the PLEA 2017 conference, and dedicated sessions on WUDAPT will be continued during PLEA 2018.

The main drawback of WUDAPT is that, as it is based on a subjective classification, it is done city by city (or 200 sometimes for a larger region), and thus is not expected to cover all cities in the world (at least not for many years). A promising way to take advantage of this improved mapping of some cities is to include them in the above-mentioned global maps, which are based on the same LCZ typology.

\section{$\underline{\text { Multi-criteria impacts }}$}

Another reason to have a finely detailed description of the city is related to the need for multi-criteria impact assessment (see section 3). For example, energy consumption due to domestic heating and air conditioning is strongly related not only to the morphology of a building, but also to its architectural fabric and use (e.g., as office, residential or

210 commercial space). Furthermore, energy consumption is linked to how people use their heating and cooling systems and what their comfort temperature is. And to assess societal impacts, this information must be intersected with societal and demographic information. Urban vegetation, its arrangement, type and even species can also influence thermal comfort, flooding mitigation and water resources.

215 Such thematic information cannot be derived from remote-sensing approaches; there is a need for bottom-up mapping, using fine-scale source data (typically at building \& road scale).

\section{(Specific) City maps from fine-scale data}

220 Many geographical studies have been performed in the past in order to provide such fine-scale and multi-parameter descriptions of cities (e.g. Lindberg $(2007)^{29}$ ). However, such urban climate-oriented fine-scale analyses on a particular city were strongly limited in reproducibility, in terms of methods, to another city, even in the same country. The reasons were twofold:

- Such analyses require strong competencies, and are generally performed specifically for a given area, by a specific urban actor or researcher

- And, even more crucial, the variety, accessibility and homogeneity of the input source data are extremely diverse and limited to the area: fine-scale building model data can be possessed by a given city and not by one nearby. Or the data may (and most often does) come in a different form and content.

230 These limitations imply that few cities have fine-scale urban data available for micrometeorological studies, and when they do it is usually owing to local action. However, spatially homogeneous information is crucial for defining standardized, or at least generalized, interfaces between urban data and meteorological models.

Some actions have been conducted on a larger territory to provide homogeneous urban description. Note that this 235 information is generally limited to land use or morphological parameters (such as building height and building density). Two examples are NUDAPT, where approximately 40 of the biggest cities in the USA were mapped using building elevation data ${ }^{30}$, and Urban Atlas, describing 305 cities of more than 50,000 inhabitants in Europe ${ }^{31}$.

However, the main drawback of these approaches is that they provide information only on the biggest cities, information that is limited to the cities' administrative boundaries. The description of the (sub)urban areas outside each 


\section{Analysis methods and impact indicators}

As pointed out in the introduction, urban climate study covers a multitude of research topics. The historical topics are mostly related to analysis and modelling of physical processes of the urban climate, interactions between surface and atmosphere, and impact on local meteorology and the atmospheric boundary layer. They are of course still being investigated by the scientific community today. Nonetheless, a new field of research has been growing continuously for several years, related to expectations of civil society and public and political stakeholders. This momentum is driven by the fact that cities are a concentration of populations, infrastructures, and economic activities, which can be affected by nuisances of various kinds and are vulnerable to a host of environmental impacts. More especially, professional actors in charge of living environments and urban planning are currently quite concerned by artificialization of pervious soils related to the urbanization process, and associated urban heat island issues that may lead to public health problems. Added to this are the local effects of climate change that could significantly exacerbate the still existing issues.

In order to provide information that is relevant and of real added value for decision makers, three main objectives must be addressed:

1. Impact studies should not be limited to one dimension but ideally cover multiple dimensions that are likely to interact, in order to produce multi-criteria indicators.

2. The physically-based data derived from numerical models or other types of sources have to be translated or transformed into information that is more directly connected to the effects on society (which can be effects on people or on the economy, for instance).

3. From a risk management point of view, the first step required in risk assessment is to evaluate the degree of vulnerability or exposure cities or populations are subjected to (the subject must be defined), as well as the hazard concerned, i.e. a type of event and the probability of its occurrence.

\section{$\underline{\text { Systemic approach }}$}

The city is a complex ecosystem where diverse and heterogeneous elements interact: built-up infrastructures, natural areas, people, plural-sectorial activities and services, etc. Present-day meteorological conditions - the weather and the way they evolve in a changing climate may influence the urban ecosystem and its functioning. Impacts may

300 concern different sectors related to the elements composing the system. And the evolution or modification of one of these elements may also impact other elements or the system as a whole. A purely disciplinary approach for impact studies is consequently limiting. Some recent research has adopted systemic and interdisciplinary approaches ${ }^{36,37}$ by 
integrating different models or enriching existing models with new processes, and by feeding the models with integrative scenarios for cities.

305 Urban climate models were initially designed to compute changes in meteorological variables at street level in a builtup environment, i.e. air temperature, humidity, wind speed. Efforts have been made recently to simulate the complexity of the urban environment more realistically. Urban vegetation in interaction with built-up elements ${ }^{38,39,40,41}$, water exchanges between atmosphere, surface and soil ${ }^{42}$, as well as building energetics ${ }^{43,44,45}$ are new developments that have been recently implemented in urban canopy models. Such configurations now make it possible to explicitly model 310 interactions between all these processes, to more accurately simulate specific adaptation strategies or urban design scenarios, and to enrich diagnoses. Urban scenarios describing how cities can evolve and which action levers can be implemented are also an important piece of this approach. They can concern various dimensions including actions on buildings and urban design and larger scale urban planning policies, as well as interventions on transportation networks, or policies that encourage inhabitants to modify their habits (transport modes, energy behaviors). Demographic trends,

315 urban expansion, architectural evolution etc. can be taken into account, based on collaborations with economists, geographers, architects or urban planners. Some of these changes can be determined from numerical modelling. In particular, long-term urban expansion can be calculated with economic models such as NEDUM ${ }^{46}$, or for shorter time periods with geographical models adjusted to past trends. Other developments, for instance related to implementation of local policies for building renovation, urban greening, or adaptation of public transportation, can be defined based on expert choices.

\section{$\underline{\text { Defining indicators }}$}

Numerous studies evaluate urban design scenarios or strategies of adaptation to climate change only by quantifying the impact on air temperature or urban heat islands. While the indicator of this impact is one relevant indicator, it can be 325 calculated in different ways, depending on the time of the day (daytime or nighttime), for a specific location, spatially averaged, and so on, which means that results and conclusions can differ.

Studies in climate-sensitive urban design look at perceived, or "feels-like", temperatures or people's thermal comfort for indoor and outdoor environments, through computation of indices such as Wet Bulb Globe Temperature (WBGT),

330 Predicted Mean Values ${ }^{47}$ (PMV), Physiological Equivalent Temperature ${ }^{48}$ (PET), and Universal Thermal Climate Index (UTCI). These indices are related to heat stress scales, which make it possible to analyze threshold exceedance. These indices are now included as diagnoses of some urban climate models for weather forecasting or impact studies. Leroyer et al $(2015)^{49}$ developed an urban-scale weather forecasting system for the 2015 PanAm Games in Toronto for the purpose of producing heat-stress maps using Humidex, UTCI, and the WBGT indices. Kusaka et al $(2012)^{50}$ and 335 Argüeso et al $(2015)^{51}$ have investigated the evolution of comfort conditions in the future using the WBGT index, based on regional climate simulation with the Weather Research and Forecasting (WRF) Model in Japanese cities and the Sydney region, respectively. Lemonsu et al $(2015)^{37}$ and Daniel et al $(2018)^{52}$ have studied the impact of urban expansion scenarios on UTCI for future heat-wave conditions over the Paris region. It is, however, difficult to decide which index to use, as well as how to analyze these indices to assess the impacts on the population in a standardized 340 manner and provide relevant urban climate services for society and users. The needs and practices can vary significantly depending on the domains of application. Thus the recent urban-climate studies related to heat stress evaluation present a wide range of approaches. Thermal comfort can be computed at the most critical hours of the day or combined over time to evaluate potential prolonged exposure to uncomfortable conditions. For instance, Argüeso et al (2015) ${ }^{51}$ investigated seasonal averages of minimum and maximum values of thermal indices and analyzed how they changed

345 over time. Kusaka et al $(2012)^{50}$ calculated the number of hours exceeding a certain heat stress threshold. Spatial analysis is also tricky. Thermal comfort can be studied as maps in order to identify sensitive areas or aggregated on the neighbourhood or city scale. Lemonsu et al $(2015)^{37}$ showed for the Paris (France) urban area that results can be substantially different if the averaging is done according to density of built covers or inhabitants.

350 Energy consumption for domestic heating and air-conditioning is also an important criterion in evaluating choices in urban design or planning. All the more so as this falls within the context of climate change and objectives in greenhouse gas reduction targeted by countries worldwide. Most urban-climate studies focus on energy consumption related to airconditioning use, which could be a major issue within a global warming context with an increase in the risk of heat waves. But it is also important to assess the potential retroaction of some adaptation measures (or UHI mitigation 355 measures) on domestic heating consumption. For instance, De Munck et al $(2018)^{53}$ indicate that some forms of urban greening are efficient ways to cool air temperature during summer but that this cooling may persist in winter and increase demand for heating.

Water resources are also crucial for impact studies and this issue has begun to be addressed, especially in connection

360 with irrigation and greening strategies, by urban models that consider water exchanges (including irrigation) and, in some cases, subsoil hydrology.

For a more objective and complete evaluation, indicators computed by urban climate models can be also put in perspective with indicators derived from urban design or planning scenarios. Urban expansion strategies, for instance, have a significant impact on $\mathrm{CO} 2$ emissions due to transportation. Economic cost, material life-cycle and carbon 
365 footprint (e.g. for building renovation or green space management) are also relevant criteria for evaluation, but they are complex to estimate.

\section{$\underline{\text { Risk evaluation }}$}

Numerous impact studies for cities are being conducted under hot summertime conditions in order to evaluate the efficiency of some adaptation levers in cooling the urban environment. Past heat wave events like the one that occurred in August 2003 have often been taken as case studies. Nonetheless this approach has two limitations. First, it focuses only on extreme heat conditions without considering multi-annual or seasonal-scale effects. This can be crucial for some adaptation choices. Notably in case of greening strategies, vegetative and hydrological cycles require longer time periods of analysis. Secondly, the representativeness of a specific meteorological event can be questioned. In a changing

375 climate, occurrence frequencies of heat waves, as well as the characteristics thereof (intensity, duration, severity) will evolve. Consequently, in order to evaluate urban vulnerability rigorously, it becomes necessary to take this statistical development into account.

\section{The integration of local climate knowledge in urban planning and urban development}

380 International collaboration cited in the introductory section does not lead only to a rich state of the art of the urban atmosphere in physical terms; it has also led to the development of a rich bibliography presenting applied knowledge about the urban climate, to be used by planners for practical purposes of urban heat-island mitigation and wind, rain and snow management and for effective use of green space to enhance air quality and human comfort. Nevertheless the application of science-based knowledge to urban design has encountered difficulties in being

385 disseminated and translated operationally, except for rare exceptions as in German-speaking countries where numerous publications exist, ranging from the earliest ones, Horsfall ${ }^{54}$ in 1904 and $\mathrm{Kratze}^{55}$ in 1937, to the most recent ones: Stock and Baumüller ${ }^{56-58}$, to cite just a few, and, to a lesser extent, in Israel ${ }^{59}$ and Japan ${ }^{60,61}$. Retrospectively, Hebbert and Mackillop ${ }^{4}$ pointed to some curbs that can account for the difficulties encountered with climate knowledge integration on the urban scale. They fall into two categories, those referring to trends in urban fabric and town planning, 390 and those related to the ways atmospheric knowledge is produced.

Concerning the urban fabric, two key aspects are put forward by the authors:

- the fact that modernism became the dominant global movement in the $20^{\text {th }}$ century for urban production. This group of styles in architecture and urban design focused more on the building scale being outdoor spaces that were often considered solely from a landscaping point of view, neglecting climatic analysis.

395 - and the fact that between the 1950s and 1970s, environmental determinism gave way to environmental constructivism, resulting in waning interest in the impact of design decisions on the physical environment.

Concerning the basis of atmospheric knowledge production, the predominant disconnection between the national meteorological services that produce atmospheric data and analysis and the territorial planning professions is often pointed out. In urban areas, the complexity of the urban atmosphere requires location-specific and high-density

400 observations, but the high cost of implementation and maintenance of standardized atmospheric measurements has made the general observational networks dependent on national meteorological services. However, given the non-urban orientation of main national weather services, which are dedicated chiefly to aviation, agriculture, weather forecasting and national defense, meteorological data were historically collected for the most part outside of urbanized areas. The shift from physical measurements to numerical models in recent decades further reinforces the centralized character of 405 the atmospheric knowledge production in the national and international meteorological services. A current action coordinated by WMO aims to correct this fact through the development of a "Guide for Integrated Urban Weather Environment Climate Services" that was open for community review in March 2018.

The laborious and expensive nature of local climate studies is nevertheless rapidly changing thanks to the development of lightweight sensors, three-dimensional urban databases that allow high resolution mapping, and GIS

410 platforms capable of being linked to multi-scalar statistical models. Collaborative data is also strongly penetrating urban climate research $^{62}$. But the widespread application of urban climatology in urban design and urban environmental planning was especially facilitated in the last decade by the rise of awareness of anthropogenic climate change that gained in importance in both public and political opinion ${ }^{63}$. The two reports entitled Cities and Climate Change published in 2011 by the United Nations and the Urban Climate Change Research Network ${ }^{64,65}$, putting forward the role

415 that cities should play in greenhouse mitigation and adaptation, played a major role in placing climate issues on the agenda at the city level. It is time for the emergence of networks of cities committed to tackling climate change at international and national levels -- networks such as C40, which was given impetus by the mayor of New York City in 2010, ICLEI - Local Governments for Sustainability, and the Global Cool Cities Alliance. The changing global climate has become, in a way, the window of opportunity for the transfer of climate knowledge on a local scale.

$420 \quad$ But what strategies and tools are available for operational application of urban climate science knowledge? Historically, the German-speaking research community has led the application of science-based climatic design with a 
systematization of local climate studies since the first half of the twentieth century. Their cartographic techniques for mapping thermal distributions, cold air lakes and flows, wind patterns, pollution concentration, etc. combining meteorological and climate information, land-use data, and terrain information have the advantage of fitting the needs of both urban planning practices and urban planning tools. Fine-grained spatial mapping started in Germany in the 1970s with The Climate Booklet for Urban Developments (1977) in Stuttgart and continued with the Klimaatlas published on 1992. The Stuttgart Klima Atlas methodology has been used in Europe, Asia, and South America, mostly adapted from the earlier German model and following the German Guidelines VDI3787 Part1 Environmental Meteorology - Climate and Air Pollution Maps for Cities and Regions, first published in 1993 and updated in 2015. In recent years, Urban Climate Maps have become a reference tool for translating scientific climatic knowledge into guidelines and planning recommendations ${ }^{66}$.

Different names are used for these cartographic tools depending on the country and scale of action, but the denomination Urban Climatic Maps (UC-Map) has been widely used in recent years. Technical choices on how to produce these cartographic tools depend on local climatological features, the available data on urban morphology and climate, and the scientific and cultural background of the actors (researchers and stakeholders) involved in the project. Climatological data can be produced through observations (permanent meteorological network or field campaigns) or modelling (often on the neighborhood scale). As atmospheric information is needed for the whole city, spatialization techniques are often used to statistically quantify the relations between the physical surface of the city and the meteorological variables, assuming that, for some specific weather situations such as anticyclonic situations with low 440 wind speed, local climate conditions within the urban canopy are mainly driven by urban surface features. Numerical simulations coupling an atmospheric model with a Soil-Vegetation-Atmosphere transfer (SVAT) model can also be used to take into account the impact of the physical surface (e.g., land use, topography, urban morphology) on the atmospheric fields and the atmospheric dynamics for the whole city scale. This approach is particularly useful for integrating the plurality of weather situations representative of a place in the cartographic reflection ${ }^{67}$.

445 In $\mathrm{Ng}$ and $\mathrm{Ren}^{66}$ and Figure 2, experiences with recent UC-Maps are presented for large, medium-sized and small cities around the world; yet it appears that only in very few cases is the translation of recommendations for urban planning derived from the climate diagnosis really taken into account at the operational level in land use zoning, design codes or green-space and water area management. Since the scientific basis and technical tools for local climatic diagnosis exist, what are the specific reasons behind the fact that climate information is successfully transferred in some 450 places, matching both policy and regulatory engagement, and not in others?

Planning advice is sometimes commissioned by practitioners and planners but often the study is promoted and funded by the producers of climatic data, who are almost always researchers; but what is observed ${ }^{67,69}$ is that all the successful examples of urban climate management entailed two key ingredients: the presence of a community research team, pushed to the extreme by the city of Stuttgart with the presence of in-house urban climatologists, and a long process of collaboration and acculturation between researchers and practitioners. It seems that research developments in urban climatology are effectively boosted by international collaborations and networks, but effective transfer and implementation are done from the bottom up. This doesn't mean that top-down setting of targets by national government for local governments is not an effective way to boost the development of environmental and climate codes at the local level $70,71,72$, but, as also pointed out by $\mathrm{Webb}^{69}$, the co-production process that allows site-specific policy and regulatory application, stabilization and institutionalization over time is usually a bottom-up phenomenon.

We are at a time when climate knowledge and experiences in co-construction at the local scale are also able to provide input when giving thought to climate problems on a global scale. The Intergovernmental Panel on Climate Change (IPCC), supported by C40, Cities Alliance, ICLEI, Future Earth, SDSN, UCLG, UN-Habitat, UN Environment and WCRP, organized a conference ${ }^{1}$ in March 2018 to inspire global and regional research on Cities and Climate

465 Change in view of the preparation of a future IPCC Special Report that will focus on Cities and Climate Change. This event aimed "to be a pivotal milestone in developing the global understanding of how climate change will impact cities and the role of cities in tackling climate change". It brought "together representatives from academia, scientific institutions, IPCC experts, national, regional and local government representatives, urban and climate change practitioners and related networks. Its outcomes will help member states, mayors and citizens deliver on the ambition of

470 the Paris Agreement, the New Urban Agenda and the Sustainable Development Goals". Several sessions in this conference were organized by IAUC members on urban climate modelling ${ }^{73}$ (Hamdi, Tapper et al., 2018), urban climate knowledge transfer $^{74}$ (Hidalgo et al. 2018) and climate services" (Baklanov et al. 2018) aiming to contribute "to establish a new contract between society and climate science in the world's cities".

\section{Conclusion/Discussions}

Urban Climate research is now an interdisciplinary field whose international association has about 1500 members. Even if the process of transnational diffusion of knowledge within the research sphere always takes time, there has been a certain degree of cohesion and maturity in the field for some decades. The accent is put here on the

1 https://www.ipcc.ch/news_and_events/PR_citiesconference_host.shtml 
difficulties encountered in disseminating and translating applied knowledge on urban climate operationally in urban planning and urban design. An overview of the recent principal efforts for knowledge transfer to society was presented in this paper through three research items at the forefront of urban climate studies: the urban data production issue, the development of analysis methods and impact indicators and the transfer to urban planning and urban development practices.

485 The conceptual approach of urban climatology through LCZ definition has been shown to be an efficient tool for dialogue between urban climate scientists and city practitioners. Such a homogeneous approach will surely help to build common methodologies of urban climate studies and transfer tools in the coming years. The IAUC community drives the international WUDAPT initiative, which aims to produce maps of most of the cities in the world classified under this standard. Several ways to gather the needed urban information (land use, morphological, architectural, and social aspects) were presented. These can either be obtained from satellite, such as in WUDAPT, or from building and street databases, such as in MAPUCE project. While the latter method was often applied locally, city per city, this methodology has begun to be extended through the use of homogeneous data sources over countries or even the world. Expertise, especially when no database or other traditional source of information exists, is also a valid method. This is the case for architectural information, which is in general available only for some buildings individually, but not 495 available or even conceptualized for larger scale, cities, regions or countries. Finally, crowdsourcing methods are also a promising way, for urban databases such as Open Street Map, or to gain architectural information.

Analysis methods and impact indicators to evaluate strategies for adaptation to climate change and urban climate mitigation constitute a field that apparently is in need of standardization, or at least, common methodologies of study. The difficulty stems from the complex systemic nature of the city, and hence of the various aspects that must be taken into account simultaneously to provide information pertinent for urban planning. This requires strong interdisciplinary and transversal analyses. This also infers that the governance and the urban-climate related questions in one city may not be the same as in another city, rendering the building of common practice difficult. A step to overcome this is to define multi-criteria indicators, that can then be evaluated by different means, through observations 505 or modelling. These can be linked to urban climate, energy consumption, population well-being, water resources, etc. Then vulnerability and risks, in both the present and future climate, can be evaluated and actions undertaken.

Finally, tools and methods to link local climate knowledge and urban planning or urban development operations have been presented, in particular cartographic tools that have been widely used in recent years. It was pointed out that effective transfer and implementation is boosted by a bottom-up co-production process that allows site-

510 specific policy and regulatory application and city empowerment over time. This fact must be taken into account by national and international meteorological services that are currently designing the future climate services on the urban scale. Anthropogenic climate change appears to be a window of opportunity to put climate issues on the urban agenda but today climate knowledge and experience in co-construction on the local scale can also contribute to the reflection on climate problems on the global scale.

515 These interdisciplinary topics were discussed mostly through their technical angle concerning methods and tools so the ideal of standardization is not axiomatic here. Knowledge transfer emerges from widely differing contexts depending on the needs and identity of both researchers and decision-makers.

\section{Acknowledgement:}

Authors wants to thanks the three volunteer reviewers for their insightful comments on this paper.

\section{References :}

[1] Oke, T.R. 1987. Boundary Layer Climates. London \& York, N. (ed.). Methuen.

[2] Oke, T.R. 1988. The urban energy balance. Prog. Phys. Geogr. 12: 471-508.

[3] Hidalgo, J., V. Masson, A. Baklanov, G. Pigeon, \& L. Gimeno. 2008: Advances in urban climate modelling. Annals of the New York Academy of Science, 1146: 354-374.

[4] Hebbert, M. \& F. Mackillop. 2013. Urban Climatology Applied to Urban Planning: A Postwar Knowledge Circulation Failure. International Journal of Urban and Regional Research. 37: 1542-1558. doi: 10.1111/14682427.12046

[5] Howard, L. 1818. The Climate of London. Publisher W. Phillips.

530 [6] Kassner, C. \& Vortrage, S. (Ed.). 1910 Die meteorologische Grundlagen des Stadtebaues. (The meteorological basics of city planning). Ernst u. Sohn

[7] WMO. 2017. Guide to Meteorological Instruments and Methods of Observation. Part II, chapters 9 and 10. World Meteorological Organization editor, 1177 pages, available online: HYPERLINK 
"https://library.wmo.int/opac/doc_num.php?explnum_id=4147"

_blankhttps://library.wmo.int/opac/doc_num.php?explnum_id=4147

[8] Barlow, J. 2014. Progress in observing and modelling the urban boundary layer. Urban Climate. 10(2): $216-240$

[9] Masson, V. 2006. Urban surface modelling and the meso-scale impact of cities. Theoretical and Applied Climatology. 84: 35-45

[10] Kanda, M. 2006. Progress in the scale modeling of urban climate: Review. Theor. Appl. Climatol. 84: 23-33

540 https://doi.org/10.1007/s00704-005-0141-4

[11] Dabberdt, W., G. Frederick, R. Hardesty, W.C. Lee \& K. Underwood. 2004. Advances in meteorological instrumentation for air quality and emergency response. Meteorol. Atmos. Phys. 87: 57-88. https://doi.org/10.1007/s00703-003-0061-8

[12] Oke T.R., G. Mills, A. Christen \& J. Voogt. 2017. Urban Climate. Cambridge University Press publisher. HYPERLINK https://doi.org/10.1017/9781139016476

[13] Stewart, I.D. \& T.R. Oke. 2012. Local Climate Zones for Urban Temperature Studies. Bull. Amer. Meteor. Soc., 93: 1879-1900, https://doi.org/10.1175/BAMS-D-11-00019.1

[14] Fenner, D., F. Meier, D. Scherer \& A. Polze. 2014. Spatial and temporal air temperature variability in Berlin, Germany, during the years 2001-2010. Urban Climate. 10: 308-331. 10.1016/j.uclim.2014.02.004.

550 [15] Leconte, F., J. Bouyer, R. Claverie \& M. Pétrissans. 2017. Analysis of nocturnal air temperature in districts using mobile measurements and a cooling indicator. Theoretical and Applied Climatology. 130(1-2): 365-376, doi: $10.1007 / \mathrm{s} 00704-016-1886-7$

[16] Keung, T.P., A. Knudby, E.S. Krayenhoff, H.C Ho, M. Brauer \& S.B. Henderson. 2016. Microscale mobile monitoring of urban air temperature. Urban Climate. 18: 58-72, ISSN 2212-0955,

555 https://doi.org/10.1016/j.uclim.2016.10.001.

[17] http://www.iau-idf.fr/savoir-faire/environnement/changement-climatique/chaleur-sur-la-ville.html

[18] Shepherd J.M. 2005. A Review of Current Investigations of Urban-Induced Rainfall and Recommendations for the Future. Earth Interactions, 9: 1-27.

[19] Dong Y., A.C.G. Varquez \& M. Kanda. 2017. Global anthropogenic heat flux database with high spatial resolution. Atmospheric Environment. 150: 276-294

[20] https://land.copernicus.eu/pan-european/corine-land-cover

[21] Pesaresi M., D. Ehrlich, S. Ferri, A. Florczyk, S.M Carneiro Freire, S. Halkia, A.M. Julea, T. Kemper, P. Soille \& V. Syrris. 2016. Operating procedure for the production of the Global Human Settlement Layer from Landsat data of the epochs 1975, 1990, 2000, and 2014. Publications Office of the European Union, 67 pages,

565 http://publications.jrc.ec.europa.eu/repository/handle/JRC97705

[22] Pesaresi M., H. Guo, X. Blaes, D. Ehrlich, S. Ferri, L. Gueguen, M. Halkia, M. Kauffmann, T. Kemper, L. Lu, M.A. Marin-Herrera, G.K. Ouzounis, M. Scavazzon, P. Soille, V. Syrris and L. Zanchetta. 2013. A Global Human Settlement Layer From Optical HR/VHR RS Data: Concept and First Results. IEEE J. Sel. Top. Appl. Earth Obs. Remote Sens. 6(5):2102-2131. doi:10.1109/JSTARS.2013.2271445.

570 [23] https://opensource.umr-cnrm.fr/projects/ecoclimap-sg/wiki

[24] www.wudapt.org

[25] Bechtel, B., P. Alexander, J. Böhner, J. Ching, O. Conrad, J. Feddema, G. Mills, L. See \& I. Stewart. 2015. Mapping local climate zones for a worldwide database of form and function of cities. Int'l J. of Geographic Information. 4(1): 199-219. doi:10.3390/ijgi4010199.

575 [26] Brousse, O, A. Martilli, M. Foley, G. Mills \& B. Bechtel. 2016. WUDAPT, an efficient land use producing data tool for mesoscale models: Integration of urban LCZ in WRF over Madrid. Urban Climate. 17: 116-134.

[27] Ching, J., G. Mills, B. Bechtel, L See, J. Feddema, X. Wang, C. Ren, O. Brousse, A. Martilli9, M. Neophytou, P. Mouzourides, I. Stewart, A. Hanna, E. Ng, M. Foley, P. Alexander, D. Aliaga, D. Niyogi, A. Shreevastava, P.Bhalachandran, V. Masson, J. Hidalgo, J. Fung, M. Andrade, A. Baklanov, W. Dai, G. Milcinski, M. Demuzere, N. 580 Brunsell, M Pesaresi, S. Miao, Q. Mu, F. Chen \& N. Theeuwes. 2018. World Urban Database and Access Portal Tools (WUDAPT), an urban weather,climate and environmental modeling infrastructure for the Anthropocene. Bulletin of American Meteorological Society. Accepted.

[28] Tornay, N., R. Schoetter, M. Bonhomme, S. Faraut, A. Lemonsu \& V. Masson. 2017. GENIUS : A methodology to define a detailed description of buildings for urban climate and building energy consumption simulations, Urban 
turbulence for urban neighbourhoods with trees. Boundary-Layer Meteorol. 156: 157-189.

[42] Stavropulos-Laffaille, X., K. Chancibault, H. Andrieu, J.-M. Brun, A. Lemonsu, V. Masson \& A. Boone. Improvements of the hydrological processes of the Town Energy Balance Model (TEB-Veg) for urban modelling and impact assessment. Submitted to Geoscientific Model Development

[43] Kikegawa Y, Y. Genchi, H. Yoshikado \& H. Kondo. 2003. Development of a numerical simulation system toward comprehensive assessments of urban warming countermeasures including their impacts upon the urban buildings energy-demands. Appl Energy. 76: 449-466

[44] Salamanca, F., A. Krpo, A. Martilli \& A. Clappier. 2010: A new building energy model coupled with an urban canopy parameterization for urban climate simulations - part I. formulation, verification, and sensitivity analysis of the model. Theor. Appl. Climatol. 99: 331.

[45] Bueno, B., L. Norford, G. Pigeon \& R. Britter. 2012: A resistance-capacitance network model for the analysis of the interactions between the energy performance of buildings and the urban climate. Building and Environment. 2012. 54: $116-125$

[46] Viguié, V., S. Hallegatte \& J. Rozenberg. 2014. Downscaling Long term socio-economic scenarios at city scale: a case study on Paris. Technol. Forecast. Soc. Chang. 87: 305-324.

[47] Fanger, PO. 1972. Thermal Comfort. McGraw-Hill Book Company.

[48] Mayer, H. \& P.R. Höppe. 1987. Thermal comfort of man in different urban environments. Theor. Appl. Climatol. 38: $43-49$

[49] Leroyer, S., S. Bélair, M. Abrahamowicz, L. Spacek, N.B., D. Theriault. 2015. Numerical weather prediction 
system dedicated to urban comfort and safety during the 2015 Pan American Games in Toronto (Canada). 9th International Conference on Urban Climate, Toulouse, France.

[50] Kusaka H., M. Hara \& Y. Takane. 2012. Urban Climate Projection by the WRF Model at 3-km Horizontal Grid Increment: Dynamical Downscaling and Predicting Heat Stress in the 2070's August for Tokyo, Osaka, and Nagoya Metropolises. Journal of the Meteorological Society of Japan. Ser. II, 90B: 47-63.

[51] Argüeso D, J.P. Evans, A.J. Pitman \& A. Di Luca. 2015. Effects of City Expansion on Heat Stress under Climate 640 Change Conditions. PLoS ONE 10(2): e 0117066.

[52] Daniel, M., A. Lemonsu, M. Déqué, S. Somot, A. Alias \& V. Masson. 2018. Benefits of explicit urban parameterization in regional climate modeling to study climate and city interactions. Climate dynamics. In press.

[53] De Munck C., A. Lemonsu, V. Masson, J. LeBras \& M. Bonhomme. 2018. Evaluating the impacts of greening scenarios on thermal comfort and energy consumption for adapting Paris city to climate change, Urban Climate, in press, doi : 10.1016/j.uclim.2017.01.003

[54 Horsfall, T.C. 1904. Improvement of the dwellings and surroundings of the people: the example of Germany. Manchester University Press, Manchester.

[55] Kratzer, A. 1937. Das Stadtklima [City climate]. Friedr. Vieweg \& Sohn, Braunschweig.

[56] Stock, P. \& W. Beckröge. 1985. Klimaanalyse Stadt Essen. KVR, PO15, Essen: Planungshefte Ruhrgebiet

650 [57] Stock P. 1992. Planning applications of urban and building climatology. Climatic classification of town areas. in K. Höschele (Ed.) Karlsruhe: Institut für Meteorologie und Klimaforschung.

[58] Baumüller J. 2005: Stuttgart21, Amt für Umweltschutz, Stuttgart, version 4

[59] Goldreich, Y. 2003. The Climate of Israel: Observation, Research and Application. Springuer

[60] Tanaka, T., T. Ogasawara, H. Koshi, H. \& S. Yoshida. 2009. Urban environmental climate maps for supporting urban-planning related work of local governments in Japan: Case studies of Yokohama and Sakai. ICUC-7. Yokohama. Japan.

[61] Kusaka, H. 2008. Recent Progress on Urban Climate Study in Japan. Geographical Review of Japan. 81(5):361374. DOI $10.4157 /$ grj.81.361

[62] Chapman L., 2015. Urban Meteorological Networks: An urban climatologists panacea? ICUC-9. Toulouse. France.

[63] Bulkeley, H. \& H. Betsill. 2003. Cities and climate change. Routledge, London.

[64] UN. 2011. Cities and climate change: UN-Habitat global report on human settlements. 18.279, Earthscan, London.

[65] UCCRN [Urban Climate Change Research Network]. 2011. Climate change and cities (first assessment report of 665 the Urban Climate Change Research Network. Edited by C. Rosenzweig, W.D. Solecki, S.A. Hammer and S. Mehrotra, 23.286, Cambridge University Press, Cambridge.

[66] Ng E., \& Ren C. 2015. The Urban Climatic Map: A Methodology for Sustainable Urban Planning. Routledge.

[67] Hidalgo, J., R. Jougla, R. Schoetter, N. Touati, V. Masson, \& K. Lau. 2018. Taking into account atmospheric dynamics and a plurality of weather situations in urban Climate Analysis maps. ICUC-10. New-York. USA.

670 [68] Hidalgo, J., S. Haouès-Jouve \& C. Ximena Lopez. 2015. Integration of urban climate issues in urban planning : reflections on which are the keys of success. ICUC-9. Toulouse. France.

[69] Webb, B. 2017. The use of urban climatology in local climate change strategies: a comparative perspective. International Planning Studies. 22(2): 68-84. 10.1080/13563475.2016.1169916

[70] Reckien, D., J. Flacke, R. Dawson, O. Heidrich, M. Olazabal, A. Foley, J.P. Hamann, H. Orru, M. Salvia, S. De 675 Gregorio Hurtado, D. Geneletti \& F. Pietrapertosa. 2014. Climate change response in Europe: what's the reality? Analysis of adaptation and mitigation plans from 200 urban areas in 11 countries. Climatic Change. 122: 331-340

[71] Marta O., S. De Gregorio Hurtado, E. Olazabal, F. Pietrapertosa, M. Salvia, D. Geneletti, V. D’Alonzo \& E. Feliú, Senatro Di Leo \& D. Reckien. 2014. How are Italian and Spanish cities tackling climate change? A local comparative study. BC3 WORKING PAPER SERIES, 2014-03

680 [72] Heidrich, O., R. J. Dawson, D. Reckien \& C. L. Walsh. 2013. Assessment of the climate preparedness of 30 urban areas in the UK. Climatic Change 120: 771-784. doi:10.1007/s10584-013-0846-9 
1

2

3

4

5

6

7

8

9

10

11

12

13

14

15

16

17

18

19

20

21

22

23

24

25

26

27

28

29

30

31

32

33

34

35

36

37

38

39

40

41

42

43

44

45

46

47

48

49

50

51

52

53

54

55

56

57

58

59

60

[73] Hamdi, I. \& N. Tapper. 2018. Urban Climate Information to Support Decision Making: From local to globa.1 Cities and climate change science conference, 2018, Edmonton, Canada

[74] Hidalgo J., Haouès-Jouve S., Medhbi Z., Bretagne G., Guilouhfi J., Lau K., Moure T., Ng E., Van-Hammers H : 685 Initiating climatic awareness in urban planning practices through participatory action research. Cities and climate change science conference, 2018, Edmonton, Canada.

[75] Baklanov, A. 2018. Guide for Integrated Urban Weather, Environment and Climate Services (IUWECS): How it can best meet the needs of researchers and stakeholders. Cities and climate change science conference, 2018, Edmonton, Canada

690

Figure legends:

Figure 1: Relation between Landscape units-maps (a), Local climate Zones (b) and near-surface air temperature (c) from bicycle measurements for a residential area close to Toulouse (Blagnac, France).

695 Figure 2: Urban Climate maps application around the world in 2018. Colors indicate the number of cities per country that initiated studies on UC-Maps and recommendations for urban planning application. Table corresponds to the date of the first published study for each city. 


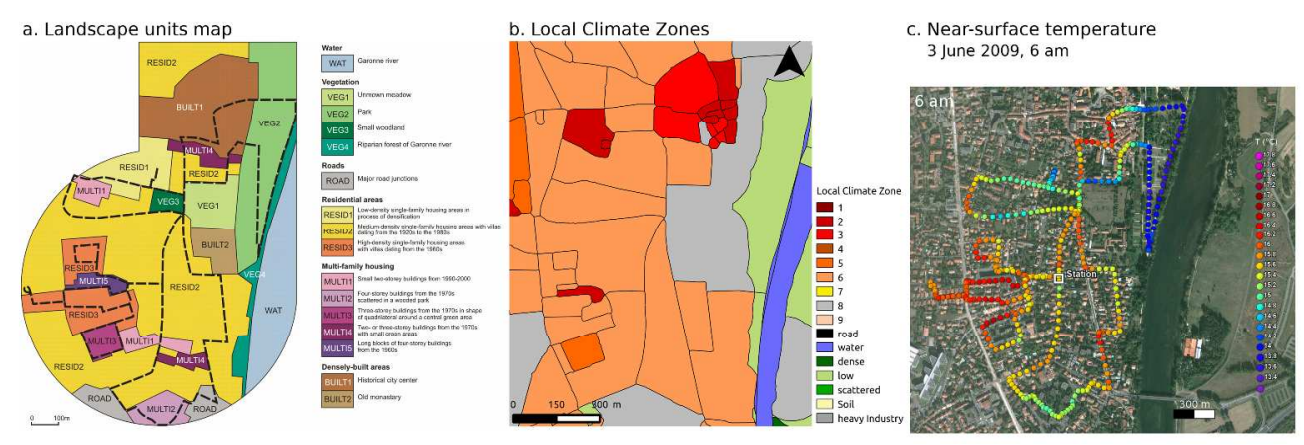

$1181 \times 389 \mathrm{~mm}(72 \times 72 \mathrm{DPI})$ 


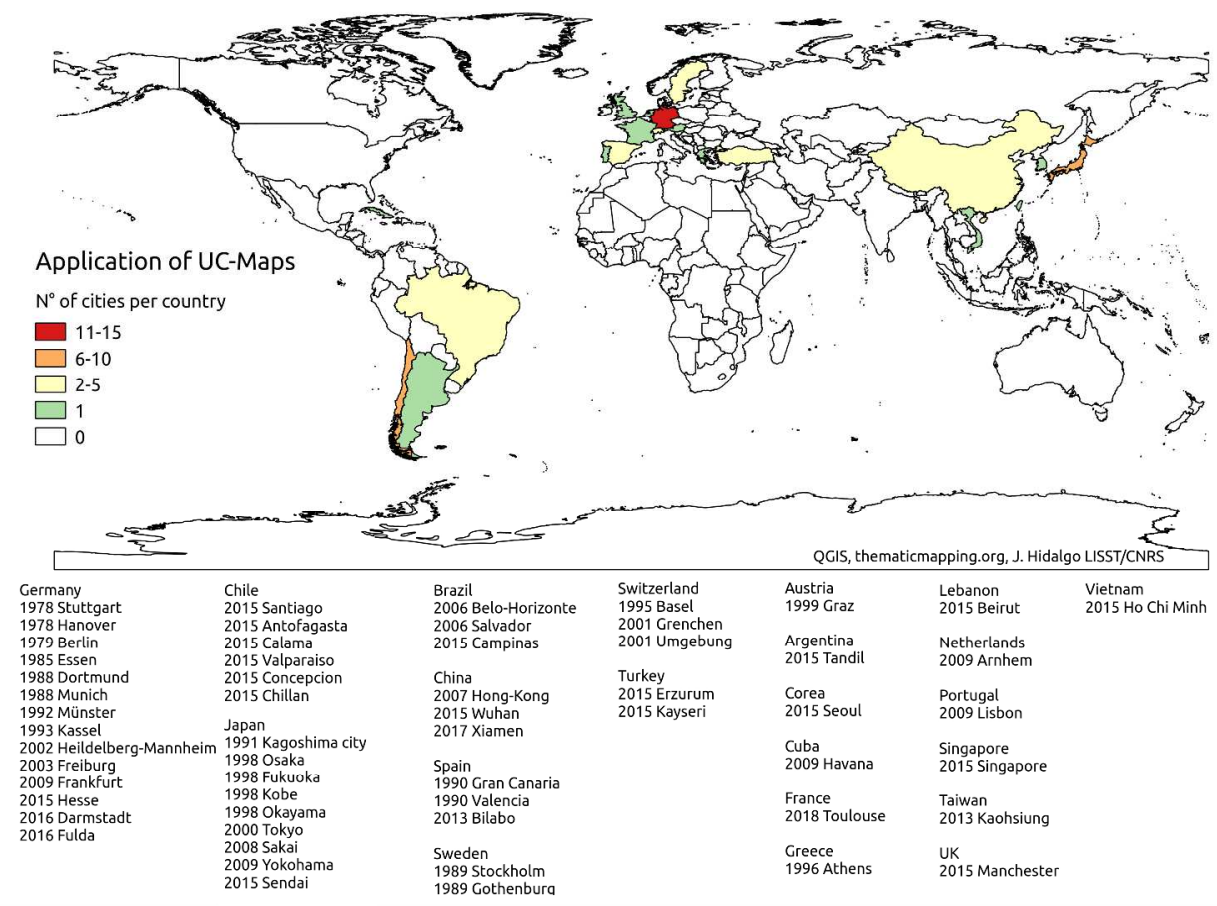

$296 \times 209 \mathrm{~mm}(300 \times 300$ DPI $)$ 